
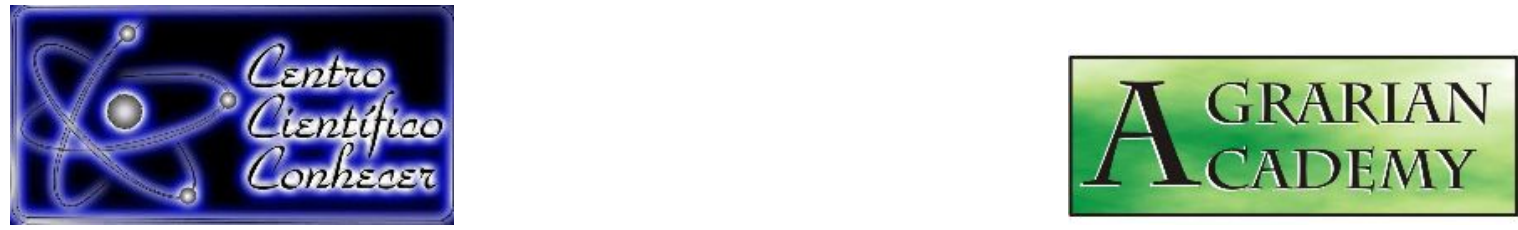

\title{
LEVANTAMENTO FITOSSOCIOLÓGICO DE PLANTAS DANINHAS E CONTROLE DE Cyperus rotundus L. COM GLIFOSATO EM PRÉ-SEMEADURA DE FEIJÃO
}

\author{
Luana Rodrigues da Cruz ${ }^{1}$, Laís Ferreira ${ }^{1}$, Reinaldo Silva Oliveira Canuto ${ }^{2}$, Débora \\ Maria Ferreira Oliveira Canuto ${ }^{3}$ \\ ${ }^{1}$ Engenheira Agrônoma, Instituto Federal do Triângulo Mineiro - Campus \\ Uberlândia, Minas Gerais, Brasil \\ 2 Professor Doutor no Instituto Federal do Triângulo Mineiro - Campus Uberlândia, \\ Minas Gerais, Brasil (reinaldo@iftm.edu.br) \\ ${ }^{3}$ Professora na UNIPAC - Campus Delta, Uberlândia, Minas Gerais, Brasil
}

Recebido em: 02/06/2019 - Aprovado em: 15/06/2019 - Publicado em: 22/07/2019 DOI: 10.18677/Agrarian_Academy_2019a19

\begin{abstract}
RESUMO
As plantas daninhas são conhecidas por competirem por recursos com o feijoeiro. Entre as espécies de plantas daninhas, a tiririca (Cyperus rotundus L.) se destaca por ser uma planta perene, de metabolismo fotossintético $\mathrm{C} 4$, muito agressiva e adaptativa. $\mathrm{O}$ objetivo deste trabalho foi realizar o levantamento fitossociológico de plantas daninhas e avaliar a eficácia de doses de glifosato no controle de $C$. rotundus em pré-semeadura do feijoeiro. Para o levantamento fitossociológico utilizou-se o método do quadrado inventário, avaliando-se: frequência, frequência relativa, abundância, abundância relativa, densidade, densidade relativa e índice de valor de importância. $C$. rotundus foi a planta daninha com maior índice de valor de importância, com $214 \%$, por isso, foram realizados os testes de eficácia do glifosato. Esse experimento foi realizado em delineamento de blocos causalizados com 7 tratamentos e 3 repetições. Os tratamentos foram constituídos pelas doses do equivalente ácido do herbicida glifosato $(0 ; 356 ; 712 ; 1068 ; 1424 ; 1780$ e $2136 \mathrm{~g}$ ha $\left.{ }^{1}\right)$. Aos 15 dias após a aplicação, foi quantificado o número de manifestações epígeas vivas, determinando-se a porcentagem e controle de tiririca. Com o levantamento fitossociológico foi verificado a presença de 6 espécies de plantas daninhas e 5 famílias. No teste de eficácia do herbicida glifosato, foi verificado o controle eficaz de $C$. rotundus quando empregado nas doses de 1424; 1780 e 2136 $\mathrm{g}$ de e. a. ha ${ }^{-1}$.
\end{abstract}

PALAVRAS-CHAVE: Fitossociologia. Herbicida. Phaseolus vulgaris. Tiririca. 


\title{
PHYTOSOCIOLOGICAL SURVEY OF WEEDS AND Cyperus rotundus L. CONTROL WITH GLYPHOSATE IN PRE-SOWING OF BEANS
}

\begin{abstract}
Weeds are known to compete for resources with beans. Among the weed species, the purple nutsedge (Cyperus rotundus L.) stands out as a perennial plant, with a very aggressive and adaptive $\mathrm{C} 4$ photosynthetic metabolism. The objective of this work was to carry out the phytosociological survey of weeds and to evaluate the effectiveness of doses of glyphosate in the control of $C$. rotundus in pre-sowing of common bean. For the floristic composition of weeds, a phytosociological survey was performed using the square inventory method, evaluated: frequency, relative frequency, abundance, relative abundance, density, relative density and importance value index. C. rotundus as being the weed with the highest index of importance value, with $214 \%$, for this reason, glyphosate efficacy tests were performed. This experiment was carried out in a causal block design with 7 treatments and 3 replicates. The treatments consisted of the acid equivalent doses of the herbicide glyphosate $\left(0,356,712,1068,1424,1780\right.$ and $\left.2136 \mathrm{~g} \mathrm{ha}^{-1}\right)$. At 15 days after application, the number of live epigene manifestations was quantified and determine the percentage and control of purple nutsedge by the herbicide. The presence of 6 and 5 weed families were verified with the phytosociological survey. In the glyphosate herbicide efficacy test, the effective control of $C$. rotundus when used at doses of $1424 ; 1780$ e 2136 g.ha ${ }^{-1}$.
\end{abstract}

KEYWORDS: Herbicide. Phytosociology. Phaseolus vulgaris. Purple Nutsedge.

\section{INTRODUÇÃO}

O feijão (Phaseolus vulgaris L.) é um alimento que está presente no dia a dia do brasileiro, principalmente como fonte alimentícia necessária para grande parte da população. Existem cerca de 14 tipos de feijão cultivados no Brasil, sendo o carioca e o feijão preto os mais conhecidos. O feijoeiro se adapta bem à vários tipos de solos e climas, sendo possível realizar até três safras durante um ano (COELHO, 2017).

A estimativa para safra $2018 / 2019$, incluindo as três safras da cultura, é que sejam produzidas 3,1 milhões de toneladas, apesar da redução da área semeada e produtividade de $24,3 \%$ no feijão de primeira safra (CONAB, 2019). Os maiores estados produtores de feijão são o Paraná (com 22,5\% da produção), Minas Gerais $(18,9 \%)$, Mato Grosso (9\%) e Bahia (8,4\%) (CONAB, 2019). A produtividade do feijoeiro é limitada principalmente pela ocorrência de fatores bióticos como pragas, doenças e plantas daninhas (BISOGNIN et al., 2019).

As plantas infestantes ou plantas daninhas são conhecidas por competirem por água, luz e nutrientes com a cultura principal instalada em campo. Em muitas situações, reduz a produtividade agrícola e dificulta a colheita. A própria espécie de planta cultivada em uma safra pode ser uma planta infestante de outra cultura sendo conduzida na safra seguinte, as quais recebem o nome de plantas voluntárias ou tigueras (ARAÚJO et al., 2018).

Dentre as espécies de plantas daninhas que causam grandes prejuízos e possuem alta taxa de infestação pode-se destacar Cyperus rotundus (L.), conhecida popularmente como tiririca, pertencente à família das Cyperaceas. Essa espécie está presente em quase todo o território brasileiro, principalmente na região do Cerrado, sendo uma planta perene, de porte baixo e altamente adaptativa. Sua 
propagação ocorre por sementes, entretanto, por possuírem uma taxa de germinação de apenas 5\%, o meio de reprodução predominante ocorre por meio de órgãos subterrâneos como tubérculos e rizomas (BELLÉ et al., 2019).

As principais estratégias de controle da tiririca dentro do manejo integrado são: capina manual ou mecânica, rotação de culturas, uso de coberturas mortas e controle químico, sendo este, devido à facilidade de uso e maior eficiência, a ferramenta mais utilizada no controle de $C$. rotundus (IQBAL et al., 2018). O glifosato é um herbicida de pós-emergência que atua na inibição da síntese de aminoácidos aromáticos, reduzindo a taxa fotossintética e inibindo o crescimento das plantas (HAMMERSCHMIDT, 2018).

O glifosato é encontrado como ingrediente ativo de diversos produtos e cada produto comercial apresenta uma combinação peculiar de surfactantes que interagem de forma muito específica com a espécie de planta daninha (GALLI; MONTEZUMA, 2005), ou seja, um produto comercial que contenha glifosato pode apresentar uma eficácia de controle de tiririca diferente de outros produtos comerciais disponibilizados por diferentes empresas que os produzem. Nesse contexto, objetivou-se com este estudo realizar o levantamento fitossociológico de plantas daninhas e avaliar a eficácia do glifosato no controle de $C$. rotundus em présemeadura do feijoeiro.

\section{MATERIAL E MÉTODOS}

O experimento foi realizado no setor de Horticultura do Instituto Federal do Triângulo Mineiro - Campus Uberlândia, cujas coordenadas de latitude e longitude são: $18^{\circ} 46^{\prime}$ 09" S e Longitude: $48^{\circ} 17^{\prime} 40^{\prime \prime} \mathrm{W}$, respectivamente. O solo do local é classificado como Latossolo Vermelho-Escuro eutrófico. De acordo com a classificação de Köppen, o clima da região é Aw, com verões chuvosos e invernos secos. O local destinado à condução dos ensaios foi cultivado com feijoeiro irrigado até o mês de novembro de 2017. O próximo cultivo de feijão deu-se a partir de agosto de 2018, com isso, realizou-se o experimento no período de abril a maio de 2018.

Para identificar as plantas daninhas presentes na área de cultivo e determinar a espécie predominante a ser controlada, foi realizado um levantamento fitossociológico no dia 25/04/2018 por meio do método do quadrado inventário (BRAUN-BLANQUET, 1979). O quadrado foi feito com tubos de PVC de $20 \mathrm{~mm}$ de diâmetro, com dimensões de 0,5 $\mathrm{m} \times 0,5 \mathrm{~m}$. Foram amostrados 21 pontos no centro de cada uma das 21 parcelas experimentais que foram demarcadas para o teste de eficácia do herbicida glifosato e registrados os indivíduos e a quantidade de cada espécie.

Cada parcela experimental apresentava $10 \mathrm{~m}^{2}$ (5 m de comprimento $\times 2 \mathrm{~m}$ de largura), havendo um espaçamento de 2 metros entre blocos e 1 metro entre as parcelas. Após a quantificação e identificação das espécies de plantas daninhas nas parcelas, os seguintes parâmetros fitossociológicos propostos por Mueller-Dombois e Ellenberg (1974) foram calculados:

Frequência:

$$
\mathrm{F}=\frac{\text { número de quadrados onde a espéciefolencontrada }}{\text { número total de quadrados }}
$$


Frequência relativa:

$$
\mathrm{Fr}=\frac{F+\text { x } 100}{\text { frequência total das aspécies }}
$$

Abundância:

$$
\mathrm{A}=\frac{\text { número total de individ uos da espécie }}{\text { número total de quadrados onde aspécie foi encontrada }}
$$

Abundância relativa:

$$
\mathrm{Ar}=\frac{\text { Ax } 100}{\text { abundância total das aspécies }}
$$

Densidade:

$$
\mathrm{D}=\frac{\text { número total de individuog da espếcie }}{\text { número total de quadrados }}
$$

Densidade relativa:

$$
\mathrm{Dr}=\frac{D \times 100}{\text { densidade total das espécies }}
$$

Índice de importância relativa:

IVI = frequência relativa + densidade relativa + abundância relativa

Após 7 dias do levantamento fitossociológico, foi realizado o teste de eficácia do herbicida glifosato, sendo o experimento realizado em blocos casualizados com 7 tratamentos e 3 repetições (quadro 1), sendo a testemunha sem aplicação de herbicida. As aplicações foram realizadas por meio de um pulverizador costal elétrico, com pressão de $60 \mathrm{lb} \mathrm{pol}^{-2}$ e volume de pulverização de $100 \mathrm{~L} \mathrm{ha}^{-1}$. As doses do herbicida foram especificadas como equivalente ácido do glifosato por hectare (e. a. ha $\left.{ }^{-1}\right)$.

QUADRO 1: Descrição dos tratamentos.

\begin{tabular}{|c|c|}
\hline Tratamento & Dose de glifosato $^{\circledR}$ (e. a. ha ${ }^{-1}$ ) \\
\hline Tratamento 1 & 356 \\
\hline Tratamento 2 & 712 \\
\hline Tratamento 3 & 1068 \\
\hline Tratamento 4 & 1424 \\
\hline Tratamento 5 & 1780 \\
\hline Tratamento 6 & 2136 \\
\hline Tratamento 7 & Testemunha \\
\hline
\end{tabular}

Aos 15 dias após a aplicação (DAP) de glifosato, foram quantificados o número e as espécies de plantas daninhas que permaneceram vivas, também com auxílio do quadrado inventário, o qual foi colocado no centro de cada parcela para a amostragem das plantas infestantes. Após a comparação do número de plantas daninhas que existiam antes da aplicação e 15 DAP, foi possível determinar a porcentagem de plantas daninhas controladas pelo glifosato, para cada nível de herbicida aplicado. A avaliação da porcentagem de controle foi determinada para a tiririca (Cyperus rotundus) porque foi a única espécie encontrada em todas as parcelas amostradas. Outras espécies foram encontradas em algumas amostragens, no entanto, a frequência foi muito baixa.

O levantamento fitossociológico foi apresentado na forma de tabelas e os dados de porcentagem de controle de $C$. rotundus foram submetidos à ANAVA, com 
aplicação do teste $\mathrm{F}$ a $5 \%$ de significância. Após esse teste, foi aplicada a análise de Regressão para a determinação do modelo polinomial que melhor se ajustava aos dados obtidos. Foi utilizado o programa estatístico SISVAR (Versão 5.3) (FERREIRA, 2013) para as análises estatísticas.

\section{RESULTADOS E DISCUSSÃO}

No levantamento fitossociológico realizado na área experimental destinada à produção de feijão, foram identificadas 6 espécies de plantas daninhas agrupadas em 5 famílias, comprovando a heterogeneidade de comunidade infestante (Quadro 2).

QUADRO 2: Espécies e famílias de plantas daninhas encontradas no levantamento fitossociológico realizado aos 7 dias antes da aplicação de glifosato.

\begin{tabular}{|c|c|c|}
\hline Família & Nome comum & Nome científico \\
\hline Amaranthaceae & Caruru & Amaranthus viridis \\
\hline \multirow{2}{*}{ Commelinaceae } & Trapoeraba & Commelina benghalensis \\
\cline { 2 - 3 } & Trapoerabinha & Murdania nudiflora \\
\hline Cyperaceae & Tiririca & Cyperus rotundus \\
\hline Euphorbiaceae & Leiteira & Euphorbia heterophylla \\
\hline Poaceae & Grama-seda & Cynodon dactylon \\
\hline
\end{tabular}

A espécie Cyperus rotundus apresentou a freqüência na ordem de 1.0, enquanto que as espécies Amaranthus viridis e Cynodon dactylon apresentaram freqüência de 0.29 (ou 29\%), seguidas por Euphorbia heterophylla e Murdania nudiflora com 0.19 e, por fim a Commelina benghalensis com 0.14 de freqüência (Tabela 1).

TABELA 1. Número de presença em quadrados (NQ), número de indivíduos (NI), frequência $(F)$, densidade $(D)$, abundância $(A)$, frequência relativa $(F r)$, densidade relativa (Dr), abundância relativa (Ar) e Índice de valor de importância (IVI) das espécies de plantas daninhas no levantamento fitossociológico.

\begin{tabular}{cccccccccc}
\hline Espécies & NI & NQ & $\mathbf{F}$ & $\mathbf{D}$ & $\mathbf{A}$ & $\mathbf{F r}$ & $\mathbf{D r}$ & $\mathbf{A r}$ & $\mathbf{I V I}$ \\
\hline A. viridis & 31 & 6 & 0.29 & 1.48 & 5.17 & 13.64 & 1.63 & 4.53 & 19.80 \\
C. benghalensis & 9 & 3 & 0.14 & 0.43 & 3.00 & 6.82 & 0.47 & 2.63 & 9.92 \\
C. dactylon & 21 & 6 & 0.29 & 1.00 & 3.50 & 13.64 & 1.11 & 3.07 & 17.81 \\
C. rotundus & 1762 & 21 & 1.00 & 83.90 & 83.90 & 47.73 & 92.88 & 73.55 & 214.17 \\
E. heterophylla & 68 & 4 & 0.19 & 3.24 & 17.00 & 9.09 & 3.58 & 14.90 & 27.58 \\
M. nudiflora & 6 & 4 & 0.19 & 0.29 & 1.50 & 9.09 & 0.32 & 1.31 & 10.72 \\
\hline Total & 1897 & 44 & 2.10 & 90.33 & 114.07 & 100.00 & 100.00 & 100.00 & 300.00 \\
\hline
\end{tabular}

De acordo com a Tabela 1, a espécie $C$. rotundus, além de apresentar a maior freqüência, também expressou a maior freqüência relativa na ordem de $47.73 \%$, maior densidade $(83.90 \%)$, maior abundância $(83.90 \%)$, densidade relativa (92.80\%), abundância relativa (73.50\%) e maior índice de valor de importância com $214.17 \%$.

A elevada frequência relativa de $C$. rotundus demonstra que a espécies estava distribuída de modo uniforme em toda a área experimental anterior ao semeio de feijão, significando, de modo geral, na espécie mais importante da área, devido 
ao alto IVI. A tiririca (C. rotundus) possui um difícil controle devido aos pseudotubérculos que permitem sua persistência no solo.

A tiririca apresenta alta taxa de produção de tubérculos em condições de clima quente e úmido, ou seja, condições encontradas no Cerrado brasileiro (ARAÚJO et al., 2015). Considerando que a avaliação fitossociológica foi realizada no mês de abril, ou seja, final do período chuvoso e temperaturas elevadas, é esperada maior surto populacional da tiririca, como observado no presente trabalho.

Com o levantamento fitossociológico realizado por Ferreira et al. (2019) na cultura do milho submetido às doses de nitrogênio, em Couto de Magalhães de Minas, foi observada a presença de 24 espécies de plantas daninhas e não foi identificada a presença de $C$. rotundus e a espécie com maior frequência relativa foi Diodia teres (mata-pasto). A ausência da tiririca pode ser explicada pelas condições climáticas da região e pela área experimental ter sido constituída, anteriormente, de uma pastagem.

Cunha et al. (2014), estudando a fitossociologia de plantas daninhas na cultura do pimentão em sistema de plantio direto e convencional, concluíram que a tiririca foi a segunda espécie com maior frequência e índice de valor de importância, seguida apenas da planta daninha bredo (Triantema portulacastrum), em sistema convencional, das 18 espécies encontradas na área. A similaridade da presença de C. rotundus, do presente estudo e do estudo de Cunha et al. (2014), pode ser explicada pela área destinada ao cultivo de olerícolas, que apresentam mais propensão em desenvolver esse tipo de planta daninha, pois resiste às práticas de controle e manejo das atividades hortícolas. No presente estudo, a área apresentava histórico de produção de olerícolas.

O controle químico é o mais empregado devido a facilidade de execução, sendo por vezes, indicada a associação com demais formas de controle. O glifosato é um herbicida pós-emergente eficaz no controle de $C$. rotundus, desde que seja aplicado em momento adequado (estágio de desenvolvimento da planta, clima, etc.).

No presente estudo, para cada $g$ do equivalente ácido de glifosato foi observado um incremento de controle igual a $16.78 \%$. No entanto, somente as doses a partir de $1424 \mathrm{~g}$ de e.a. ha $^{-1}$ foram eficazes no controle químico da tiririca.

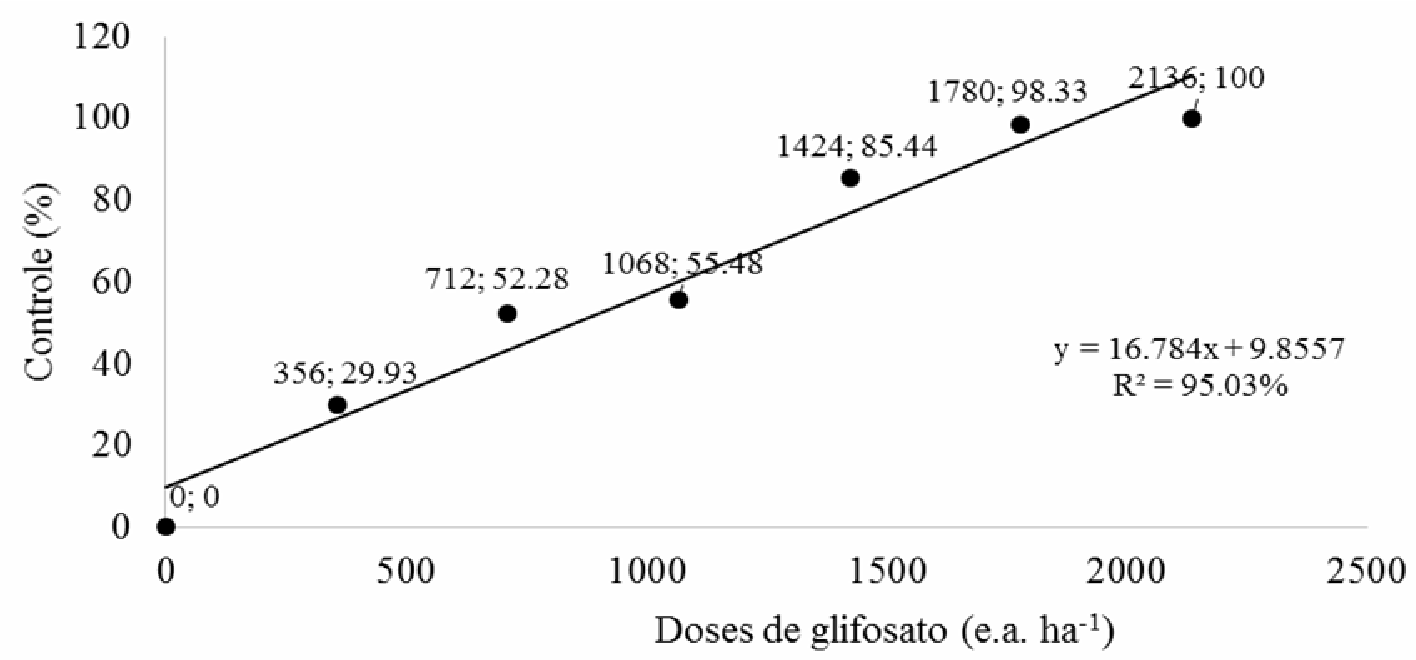

FIGURA 1. Porcentagem de controle de Cyperus rotundus, aos 15 dias após a aplicação do glifosato. $C V=12.95 \%(p<0,01)$. 
Webster et al. (2008) desenvolveram pesquisas no sentido de determinar a dose de glifosato, na forma de sal de isopropilamina, adequada para controlar tanto a parte aérea quanto os pseudo-tubérculos. Utilizando a dose de $2,57 \mathrm{~kg} \mathrm{ha}^{-1} \mathrm{em}$ plantas com idade de 5 semanas, foi constatado uma eliminação $95 \%$ e $75 \%$ da parte aérea e dos pseudo-tubéculos.

Em um estudo realizado por Silva Terceiro et al. (2016), foi observado que a competição entre o feijão-caupi e a tiririca, propiciou menor crescimento da cultura comercial, pela utilização dos recursos, como luz, água e nutrientes pela planta daninha. Demonstra-se então, a importância do controle da tiririca em présemeadura do feijão.

Anunciação et al. (2018), avaliando a associação do glifosato a herbicidas para o controle de tiririca na cultura do café, concluíram que a associação com diferentes moléculas de herbicidas, glifosato + metsulfurom metílico, glifosato + carfentrazona etílica, glifosato + flumioxazina, não diferem da porcentagem de controle aplicando-se somente glifosato.

Freitas et al. (1997) avaliaram a eficácia do controle da tiririca pelo herbicida glifosato na cultura da cana-de-açúcar. Quando pulverizado em aplicação única aos 20 dias após o plantio, na dose de $1500 \mathrm{~g}$ i.a. ha $^{-1}$, o glifosato reduziu o número de plantas em $68,9 \%$ e o número de tubérculos em $74,6 \%$. Em aplicação sequencial aos 20 e 45 dias após o plantio $\left(1500+1500 \mathrm{~g}_{\text {i.a }}\right.$ ha $\left.^{-1}\right)$, o herbicida eliminou $90,8 \%$ de $C$. rotundus na área de cultivo de cana.

A dose de $2136 \mathrm{~g}$ de e. a. ha ${ }^{-1}$ apresentou quase $100 \%$ de controle da tiririca (Figura 1), mas é importante observar a relação custo $x$ benefício do produto para uma dose tão alta. Optar pelo uso da dose de $1424 \mathrm{~g}$ de e. a. ha ${ }^{-1}$ associado à outra prática de manejo pode ser mais viável economicamente. Desse modo, novas pesquisas são necessárias para recomendação de práticas dentro do manejo integrado de $C$. rotundus.

\section{CONCLUSÃO}

O levantamento fitossociológico permitiu determinar que a tiririca (Cyperus rotundus) foi a planta daninha predominante na área. O herbicida glifosato foi eficaz no controle de $C$. rotundus até os 15 dias após a aplicação empregando-se as doses de $1424 ; 1780$ e $2136 \mathrm{~g}$ de e. a. ha ${ }^{-1}$.

\section{REFERÊNCIAS}

ANUNCIAÇÃO, A. A.; PEREIRA, R. G.; SILVA, T. B. G.; MIRANDA, G. R. B. ; ALVES, A. D.; FIGUEIREDO, F. C. Associação do glyphosae a herbicidas no controle de tiririca em cafeeiro. In: Congresso Brasileiro da Ciência das Plantas Daninhas, 2018, Rio de Janeiro: CbCPD, 2018. v. 31. Disponível em: https://www.researchgate.net/publication/330857372_Associacao_do_glyphosate_a_ herbicidas_no_controle_de_tiririca_em_cafeeiro

ARAÚJO, L. S.; CUNHA, P. C. R.; SILVEIRA, P. M.; NETTO, M. S.; OLIVEIRA, F. C. Potencial de cobertura do solo e supressão de tiririca (Cyperus rotundus) por resíduos culturais de plantas de cobertura. Revista Ceres, v. 62, n. 5, 2015. Disponível em: DOI: http://dx.doi.org/10.1590/0034-737X201562050009 
ARAÚJO, K. C.; SILVEIRA JÚNIOR, M. A.; FERREIRA, E. A.; SILVA, E. B.; PEREIRA, G. A. M.; SILVA, D. V.; LIMA, R. C. Crescimento do feijoeiro sob efeito de adubação e competição com plantas daninhas. Nativa, v. 6. n. 1, p. 20-26, 2018. Disponível em: DOI: http://dx.doi.org/10.31413/nativa.v6i1.4686

BELLÉ, C.; KASPARY, T. E.; BALARDIN, R. R.; ANTONIOLLI, Z. I. Detection of Meloidogyne graminicola parasitising Cyperus rotundus in Rio Grande do Sul, Brazil. Australasian Plant Pathology Society, v. 14, n.2, 2019. Disponível em: DOI: https://doi.org/10.1590/s0100-83582017350100006

BISOGNIN, M. B.; PIAS, O. H. C.; VIAN, A. L.; BASSO, C. J.; SANTI, A. L. Seed spacing variability reduces common bean yield. Pesquisa Agropecuária Tropical, Goiânia, v. 49, 2019. Disponível em: < https://www.revistas.ufg.br/pat/article/view/55134/33002 >

BRAUN-BLANQUET, J. Fitossociologia: bases para elestudio de las comunidades vegetales. Madri: H. Blume, 1979. 820 p.

COELHO, J. D. Produção de Grãos: Feijão, Milho e Soja. 2017. Disponível em: <https://www.bnb.gov.br/documents/80223/2789548/19_graos_11.

2017.pdf/453bc21b-eb4c-3d66-3e61-7f825669a2ad>.

COMPANHIA NACIONAL DE ABASTECIMENTO (Conab). Acompanhamento da safra brasileira de grãos - safra 2018/2019: Oitavo levantamento. Brasília, v. 6, n. 8, 2019. Disponível em: < https://www.conab.gov.br/info-agro/safras/graos/boletimda-safra-de-graos>

CUNHA, J. L. L.; FREITAS, F. C. L.; COELHO, M. E. H.; SILVA, M. G. O.; SILVA, K. S.; NASCIMENTO, P. G. M. L. Fitossociologia de plantas daninhas na cultura do pimentão nos sistemas de plantio direto e convencional. Revista Agro@mbiente On-line, v. $8, \quad$ n. 1, p. 119-126, 2014. Disponível em: DOI: http://dx.doi.org/10.18227/1982-8470ragro.v8i1.1647

FERREIRA, D.F. SISVAR software: versão 6.0. Lavras: DEX/UFLA, 2013. Software.

FERREIRA, E. A.; PAIVA, M. C. G.; PEREIRA, G. A. M.; OLIVEIRA, M. C.; SILVA, E. $B$. Fitossociologia de plantas daninhas na cultura do milho submetida à aplicação de doses de nitrogênio. Revista de Agricultura Neotropical, Cassilândia-MS, v. 6, n. 2, p. 100-107, 2019. Disponível em: DOI: https://doi.org/10.32404/rean.v6i2.2710

FREITAS, R. S.; SILVA, A. A.; FERREIRA, F. A.; SEDIYAMA, T. Efeitos do flazasulfuron do glyphosate em aplicações única e sequencial sobre o controle da tiririca (Cyperus rotundus L.). Ceres, v. 44, n. 256, 1997. Disponível em: < http://www.ceres.ufv.br/ojs/index.php/ceres/article/view/2446>

GALLI, A. J. B.; MONTEZUMA, M. C. Alguns aspectos da utilização do herbicida glifosato na agricultura. São Paulo: Acadcom Gráfica e Editora Ltda, 2005. 67 p.

HAMMERSCHMIDT, R. How glyphosate affects plant disease development: it is 
more than enhanced susceptibility. Pest Management Science, v. 74, p. 1054 1063. 2018. Disponível em: DOI: http://dx.doi.org//10.1002/ps.4521

IQBAL, J.; ZAHRA, S. T.; AHMAD, M.; SHAH, A. N.; HASSAN, W. Herbicidal potential of dryland plants on growth and tuber sproutingin purple nutsedge (Cyperus rotundus). Planta Daninha, v. 36, 2018. Disponível em: DOI: http://dx.doi.org/10.1590/s0100-83582018360100001

MUELLER-DOMBOIS, D.; ELLEMBERG, H. A. Aims and methods of vegetation ecology. New York: John Wiley, 1974. 574 p.

SILVA TERCEIRO, E. N.; PESSÔA, U. C. M.; SOUZA, A. S.; SOARES FILHO, A. A.; PIMENTA, T. A. Aspectos fisiológicos do feijão-caupi e crescimento de tiririca (Cyperus rotundus L.) sob competição em solo compactado. Revista Verde de Agroecologia e Desenvolvimento Sustentável, v. 11, n. 1, p. 14-22, 2016. Disponível em: DOI: http://dx.doi.org/10.18378/rvads.v11i1.4069

WEBSTER, T. M.; GREY, T. L.; DAVIS, J. W.; CULPEPPER, A. S. Glyphosate hinders purple nutsedge (Cyperus rotundus) and yellow nutsedge (Cyperus esculentus) tuber production. Weed Science, v. 56, n. 05, p.735-742, 2008. Disponível em: DOI: http://dx.doi.org/10.1614/ws-07-188.1. 